\title{
Antimicrobial activity of three medicinal plants against acne-inducing bacteria Propionibacterium acnes
}

\author{
S. E. Abiya ${ }^{1}{ }^{,}$, , B. O. Odiyi ${ }^{1}$, L. R. Falarunu ${ }^{1}$ and N. U. Abiya ${ }^{2}$ \\ ${ }^{1}$ Biology Department. Federal University of Technology. Akure. \\ *Email: esabiya@futa.edu.ng. \\ ${ }^{2}$ Department of Pharmacology and Therapeutics. University of Ibadan.
}

\begin{abstract}
The antimicrobial activities of three medicinal plants (Senna alata L., Azadirachta indica A. Juss, and Aloe vera (L.) Burm.f.) against pimples causing bacterium Propionibacterium acnes was studied using disc diffusion method. Extracts from each plant were used on the bacterium at three different dosage concentrations $(0.1 \mathrm{~mL}, 0.15 \mathrm{~mL}$ and $0.2 \mathrm{~mL})$. Their Zone of inhibition was measured in millimeter $(\mathrm{mm})$ and compared against a known synthetic standard (Gentamycin). Results indicate that the plants differ significantly in their activity against the studied microorganism. S. alata had the highest inhibitory effect of all the plants used $(26.00 \mathrm{~mm}, 30.67 \mathrm{~mm}$ and $36.00 \mathrm{~mm}$, for $0.1 \mathrm{~mL}, 0.15 \mathrm{~mL}$ and $0.2 \mathrm{~mL}$ dosage concentration, respectively). This was followed by $A$. indica with $9.33 \mathrm{~mm}$, $15.67 \mathrm{~mm}$ and $16.67 \mathrm{~mm}$ zone of inhibition for $0.1 \mathrm{~mL}, 0.15 \mathrm{~mL}$ and $0.2 \mathrm{~mL}$ dosage concentration respectively. A. vera had no effect ( $0.0 \mathrm{~mm}$ zone of inhibition) at $0.1 \mathrm{~mL}$ and $0.15 \mathrm{~mL}$ dosage concentrations, but at $2.0 \mathrm{~mL}$ dosage concentration, $4.0 \mathrm{~mm}$ zone of inhibition was achieved. Gentamycin showed zones of inhibition of $17.33 \mathrm{~mm}, 26.67 \mathrm{~mm}$ and $22.67 \mathrm{~mm}$, for $0.1 \mathrm{~mL}$, $0.15 \mathrm{~mL}$ and $0.2 \mathrm{~mL}$ dosage concentration, respectively. A comparison of all result obtained from the three plant extracts and gentamycin shows that $S$. alata have a significantly higher $(\mathrm{p}<0.05)$ inhibitory effect against the pimples causing bacterium; Propionibacterium acnes than all the other treatments. The trend follows $S$. alata $>$ Gentamycin $>A$. indica $>$ A. vera, respectively, in terms of their inhibitory effect. Therefore, S. alata is more active and is the most appropriate plant to be used for treating of acne vulgaris among the three plant species selected for this experiment.
\end{abstract}

Keywords: Propionibacterium acnes; Antimicrobial; Zone of inhibition; Medicinal plants.

\section{Introduction}

The use of herbs and medicinal plants is a universal phenomenon. Every culture on earth has relied on the huge
Received

August 11, 2018

Accepted

August 24, 2018

Released

August 31, 2018

Full Text Article

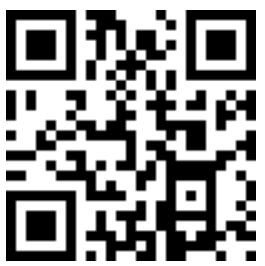

ORCID

(1) 0000-0002-9155-2307

S. E. Abiya

(ㄷ) 0000-0002-4079-9895 B. 0. Odiyi

(1) 0000-0002-2601-5839 L. R. Falarunu

(D) 0000-0001-8972-6374 N. U. Abiya variety of natural chemistry found in healing plants for their therapeutic properties. As reported by Serrentino (1991), the World Health Organization (WHO) observed that about $80 \%$ of the 
world population use medicinal plants to treat human disease. Plants have been reported to be antimicrobicidal and as such, some of them are capable of inhibiting the growth of microorganism (Heinrich et al., 2004).

Acne vulgaris is a chronic inflammatory disorder of the pilosabaceous follicles that affects more than $85 \%$ of adolescents and young adults (Hanna et al., 2003). Acne vulgaris is a common chronic skin disease involving blockage and/or inflammation of pilosebaceous units (hair follicles and their accompanying sebaceous gland). Acne can occur as non-inflammatory lesions, inflammatory lesions, or a mixture of both, affecting mostly the face but also the back and chest (Dawson and Dellavalle, 2013). According to Thiboutot et al. (2009), acne develops as a result of interplay of the following four factors: follicular epidermal hyperproliferation with subsequent plugging of the follicle, excess sebum production, the presence and activity of the commensal bacteria Propionibacterium acnes, and subsequently inflammation. P. acnes is an anaerobic organism present in acne lesions. The presence of P. acnes promotes inflammation through a variety of mechanisms. P. acnes stimulate inflammation by producing proinflammatory mediators that diffuse through the follicle wall (Kim et al., 2002).

Most teenagers suffer from this common skin problem. In a Nigerian survey reported by Husain (2009), a $90.7 \%$ prevalence of acne among teenagers was observed. In the survey, a total of 539 (274 males, 265 females) randomly selected teenagers between the ages of 11-19 years, 379 out of 418 teenagers examined had acne.

For many years, antibiotics have been used to treat acne vulgaris, however, antibiotic resistance has been increasing in prevalence within the dermatologic setting (Swanson, 2003).
The development of antibiotic resistance is multifactorial, including the specific nature of the relationship of bacteria to antibiotics, how the antibacterial is used, host characteristics, and environmental factors. To overcome the problem of antibiotic resistance, medicinal plants have been extensively studied as alternative treatments for diseases.

This research aims at determining the susceptibility of Propionibacterium acnes to the ethanolic extracts of Azadirachta indica A. Juss, Aloe vera and Senna alata L. and to compare the antibacterial activity between each active plant material against a known synthetic anti-acne agent as standard (Gentamycin).

This may lead to the discovery of an alternative form of treatment other than antibiotics being used at present, to which many of the bacteria are developing resistance.

\section{Materials and method}

\section{collection \\ Plant materials and sample}

Leaves of Azadirachta indica were collected from The Federal University of Technology, Akure (FUTA) Campus. The pulp of Aloe vera was collected from Isikan in Akure and was planted in a pot for three months before use. Senna alata leaves were collected from Ijare Town near Akure. Specimens were prepared and brought to the Department of Biology Laboratory, the Federal University of Technology Akure for further processing.

\section{Aloe vera gel extraction}

A. vera plant was collected from the pot where they were planted. The extract was prepared by cutting the aloe leaves and collecting the yellow liquid that came from the open part of the leave. The gel was also collected and mixed with the liquid. The mixture was subjected to phytochemical analysis. 


\section{Azadirachta indica and Senna alata leave extraction}

A slightly modified method by Hubert et al. (2012) was adopted for the extraction of Azadirachta indica and Senna alata leaves. Collected leave samples of both plants were air dried and pulverized using Marlex blender. $100 \mathrm{~g}$ of each pulverized leaves were weighed using JA 3003 Electronic Balance. The weighed samples were soaked in $400 \mathrm{~mL}$ of $99.9 \%$ ethanol and the mixture swirled intermittently. After $24 \mathrm{~h}$, the ethanolic extracts were separated using rotary evaporator (Resona Labo Rota 300, Type: SW 200). A portion of each extract obtained was subjected to phytochemical analysis and the remainder stored in the refrigerator until further use.

\section{Phytochemical screening of different extracts}

The presence of various phytochemical constituents in the extracts was evaluated qualitatively (alkaloids, flavonoids, phenol, saponins, steroids, tannins, terpenoids, glycosides and fixed oils). The test for alkaloid was conducted according to Siddiqui and Ali (1997). The production of a white yellowish precipitate at the addition of few drops of Mayer's reagent indicates presence of alkaloids. Shindo's test was used for the determination of flavonoids. Phenol and Tannin was tested for by the addition of ferric chloride solution. Libermann-Burchard Test was used to test for Steroids and Terpenoids as described by Harborne (1996). Saponin was determined by Froth test. The test solution mixed with distilled water is shaken thoroughly. Copious lather formation indicates the presence of saponin. Shindo's test is used to determine the presence of flavonoids. To $2 \mathrm{~mL}$ the test solution, a few magnesium turnings and a few drops of concentrate hydrochloric acid were added and boiled for $5 \mathrm{~min}$. Appearance of red or orange red colour indicates the presence of flavonoid. Glycoside is determined by mixing the extract with a little anthrone on a watch glass. One drop of concentrate sulphuric acid was added and made into a paste and warmed gently over the water bath. Dark green colouration indicates the presence of glycosides. Spot test was used in determining fixed oil. A small quantity of powder/extract was pressed between the filter papers. Formation of grease spot indicates the presence of fixed oils and fats.

\section{Isolation of $P$. acnes}

Following the standard microbiological procedure, $P$. acnes were collected from acne patients using swab stick. A total of 10 patients were randomly selected from a population of acne patients and from them; the bacteria were isolated from mature pimple papules without blood contamination from around their nose region.

\section{Biochemical test and bacterium identification}

Masamichi et al. (1980), stated the biochemical and physical tests needed for the identification of Propionibacterium acnes. The following tests were conducted to ensure that it was $P$. acnes that grew on the culture medium.

\section{Catalase test}

Using a sterile wooden applicator stick, a small amount of organism from a well-isolated 78 to $96 \mathrm{~h}$ colony was collected and placed on a microscopic slide. Using a dropper, a drop of $3 \% \mathrm{H}_{2} \mathrm{O}_{2}$ was added onto the organism on the microscopic slide without mixing. This was immediately covered and observed for immediate bubble formation $\mathrm{CO}_{2}+$ water $=$ bubbles). The production of bubbles indicates that the organism is positive for the test.

\section{Litmus milk test}

This test is used to determine the ability of the bacterium to ferment 
lactose. A Lactose broth was used. The broth was inoculated with inoculating loop. This is followed by the addition of Phenol red indicator. A yellow colouration after the addition of the indicator indicates a positive test (indicating lactose fermentation).

\section{Gram staining}

A heat fixed bacterial smear was taken and flooded with Crystal Violet and allowed to stand for $1 \mathrm{~min}$ and then washed with running water. The slide containing the heat fixed and the stained smear was again flooded with Iodine solution and allowed to stand for $1 \mathrm{~min}$, then washed with water. Ethanolacetone was then added and quickly washed off with water to discolourise the smear. A drop of Safranin red was added and allowed to stay for $1 \mathrm{~min}$, then washed off with water. The smear was blotted; air dried and observed under 100x objective lens. Pink coloured cells indicate a positive test.

\section{Inoculation of $P$. acnes}

The microorganism was grown in the laboratory following Masamichi et al. (1980) method with slight modification using Tryptic Soy Agar (TSA) instead of his proposed medium. The medium formulated contained $30 \mathrm{~g}$ tryptic soy broth, $20 \mathrm{~g}$ agar agar, $10 \mathrm{~g} \mathrm{NaCl}, 10 \mathrm{~mL}$ glycerol (4 M) and $10 \mathrm{~g}$ yeast. All was dissolved in 1,000 $\mathrm{mL}$ of distilled water. The medium was sterilized in an autoclave and used to culture the microorganism. For the primary isolation, the culture was incubated at $36^{\circ} \mathrm{C} \pm 4$ for 4 days, while subsequent incubation was for 3 days.

\section{Antibacterial assay}

Agar Well Diffusion Method was adopted for the evaluation of antimicrobial activity. From the pure culture plate of $P$. acnes already cultivated, a sub-culture was done using pure plate technique. A total of 36 plates were cultivated and a well approximately $9 \mathrm{~mm}$ in diameter bored on the surface of the agar medium using a sterile cork borer. Extracts of $A$. vera, A. indica and Salata, and $10 \mu \mathrm{g} / \mathrm{mL}$ Gentamycin (serving as the standard) were introduced into the well at 3 different concentrations $(0.1 \mathrm{~mL}, 0.15 \mathrm{~mL}$ and 0.2 $\mathrm{mL}$, respectively). The whole set up was replicated thrice. All the plates were incubated at $36{ }^{\circ} \mathrm{C} \pm 4$ for 4 days.

At the end of the incubation, the plates were observed for growth and inhibition. The diameter of the zones of inhibition was measured in millimeter $(\mathrm{mm})$ and the records taken.

\section{Statistical analysis}

All data were expressed as mean \pm standard deviation. Analysis of variance was performed by ANOVA using the SPSS software (version 21.0 for windows). Significant differences between means were determined by Tukey new multiple-range test. A significant difference was considered at the level of $\mathrm{P}<0.05$.

\section{Result}

The result of the phytochemical screening of the test plants (Aloe vera, Azadiratcha indica and Senna alata) indicate the presence of glycosides, saponins,tannins, terpenoids, phenols and flavonoids in all three plants. This is shown in Table 1. 
Table 1. Phytochemical analysis of the three nigerian plants used.

\begin{tabular}{|l|l|c|c|c|}
\hline Plant species & & A. vera & A. indica & S. alata \\
\hline \multirow{5}{*}{$\begin{array}{c}\text { Phytochemical } \\
\text { Constituents }\end{array}$} & Glycosides & + & + & + \\
\cline { 2 - 5 } & Alkaloids & + & - & + \\
\cline { 2 - 5 } & Saponins & + & + & + \\
\cline { 2 - 5 } & Steroids & + & + & + \\
\cline { 2 - 5 } & Tannins & + & - & - \\
\cline { 2 - 5 } & Resins & - & - & + \\
\cline { 2 - 5 } & Volatile Oil & - & + & + \\
\cline { 2 - 5 } & Terpenoids & + & + & + \\
\cline { 2 - 5 } & Phenols & + & + & + \\
\cline { 2 - 5 } & Flavonoids & + & & \\
\hline
\end{tabular}

$+=$ Present $-=$ Absent

The result of the biochemical and physical observation of the bacteria colony is shown in Table 2. It indicates a bacillus that test positive to gram staining, catalase test and litmus test.

Table 2. Biochemical test and physical observation of the bacterium colony.

\begin{tabular}{|l|c|}
\hline Test & Observation \\
\hline Gram's staining & Positive (+) \\
\hline Catalase & Positive (+) \\
\hline Litmus milk & Positive (+) \\
\hline Shape & Rod-Like (Baccilus) \\
\hline Colour on agar & Glistering milk \\
\hline
\end{tabular}

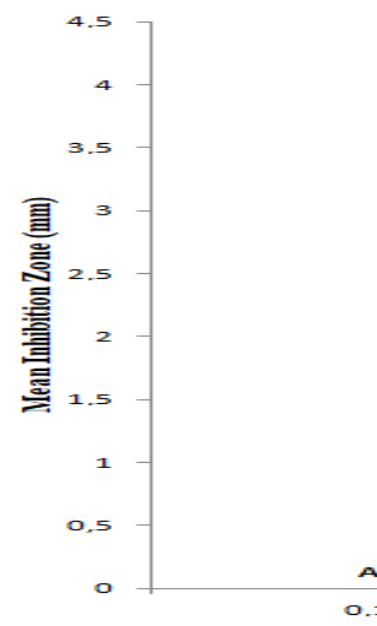

The result of the inhibitory effect of Aloe vera against the growth of Propionibacterium acnes shows that at $0.1 \mathrm{~mL}$ and $0.15 \mathrm{~mL}$ dosage concentration, no inhibition was attained but at $0.2 \mathrm{~mL}$ a $4.0 \mathrm{~mm}$ zone of inhibition was achieved. This is shown in Figure 1.

The result of the inhibitory effect of $A$. indica leaf extract as an antibacterial agent on the growth of $P$. acnes is presented in Figure 2. It shows that leaf extracts of $A$. indica applied at $0.15 \mathrm{~mL}$ and $0.2 \mathrm{~mL}$ had a significantly higher zone of inhibition when compared $0.1 \mathrm{~mL}$ dosage concentration $(16.2 \mathrm{~mm}$, $15.5 \mathrm{~mm}$ and $9.6 \mathrm{~mm}$, respectively) at $\mathrm{p}<0.05$.

\section{Dosage concentration (mL)}

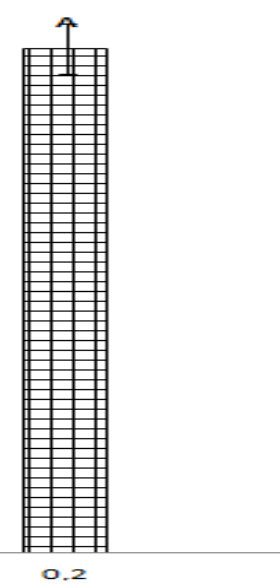

Figure 1. Inhibitory effect of Aloe vera on Propionibacterium acnes. 


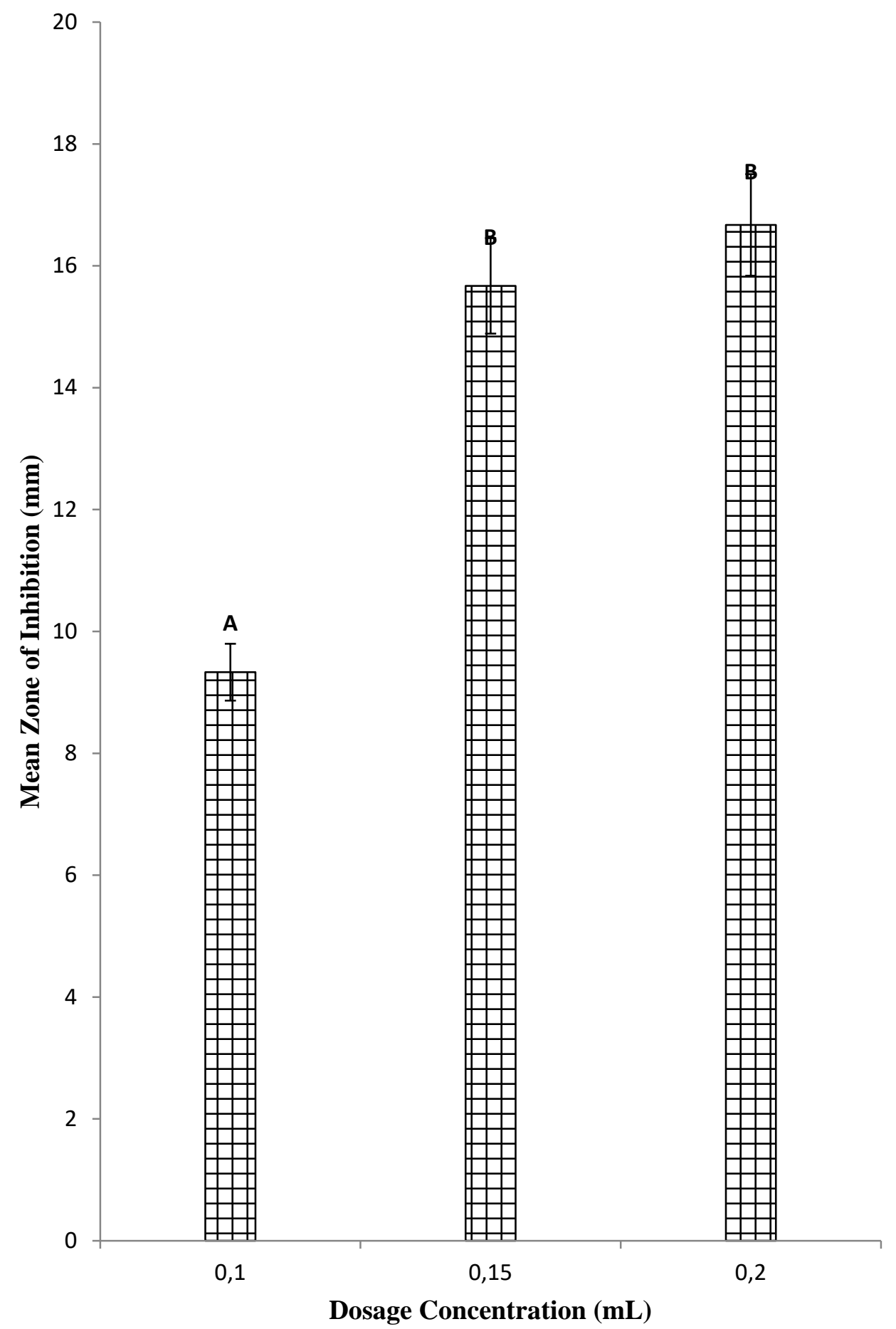

Figure 2. Inhibitory effect of Azadirachta indica on Propionibacterium acnes.

The result of the inhibitory effect of synthetic Gentamycin as an antibiotic on the growth of $P$. acnes is presented in Figure 3. 


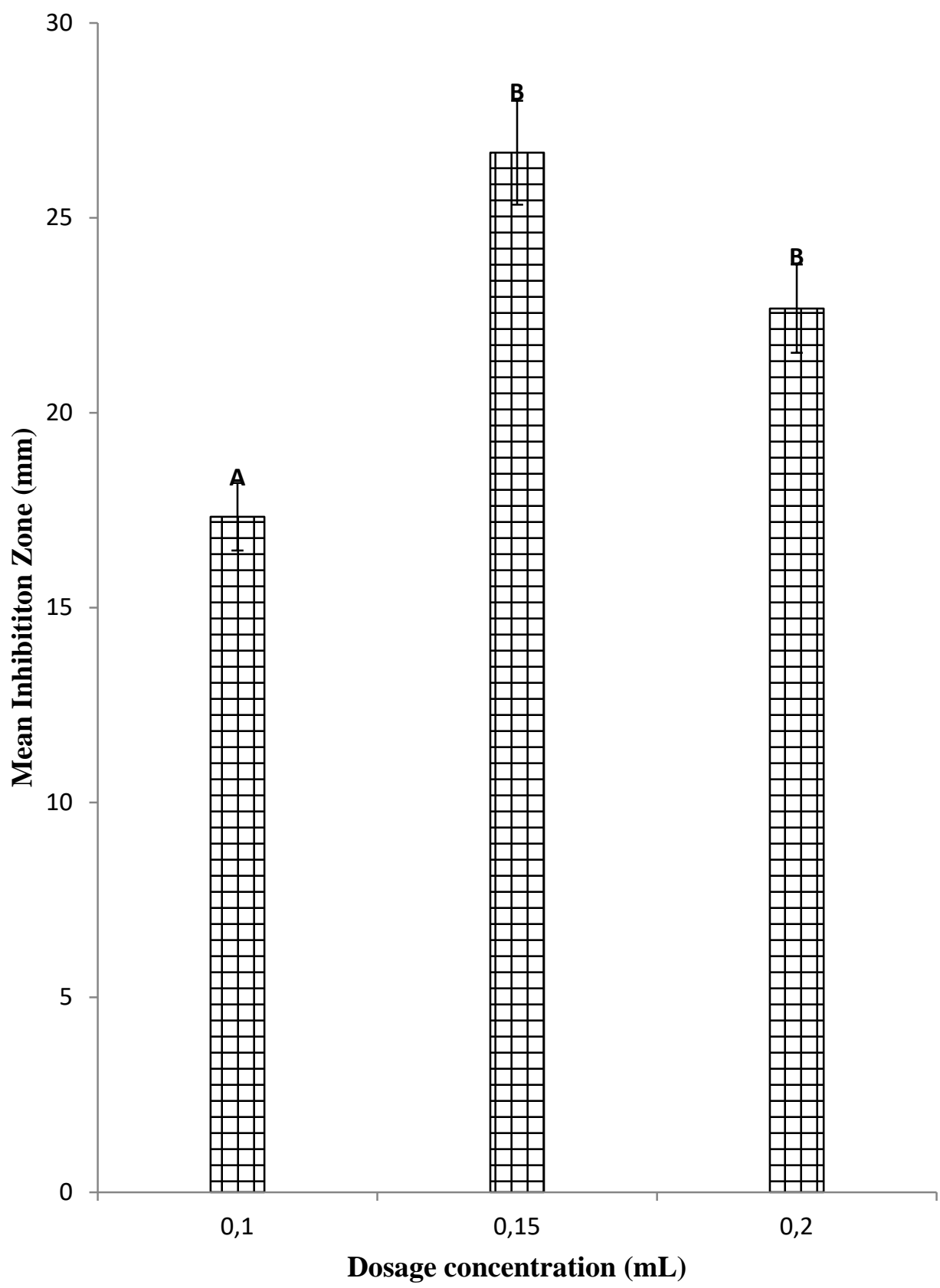

Figure 3. Inhibitory effect of Gentamycin on Propionibacterium acnes.

Highest inhibition was attained when $0.15 \mathrm{~mL}$ dosage concentration $(27 \mathrm{~mm})$. This was significantly higher than that obtained at $0.1 \mathrm{~mL}(17 \mathrm{~mm})$ at $\mathrm{p}<0.05$.
The result of the inhibitory effect of synthetic Gentamycin as an antibiotic on the growth of $P$. acnes is presented in Figure 4. 


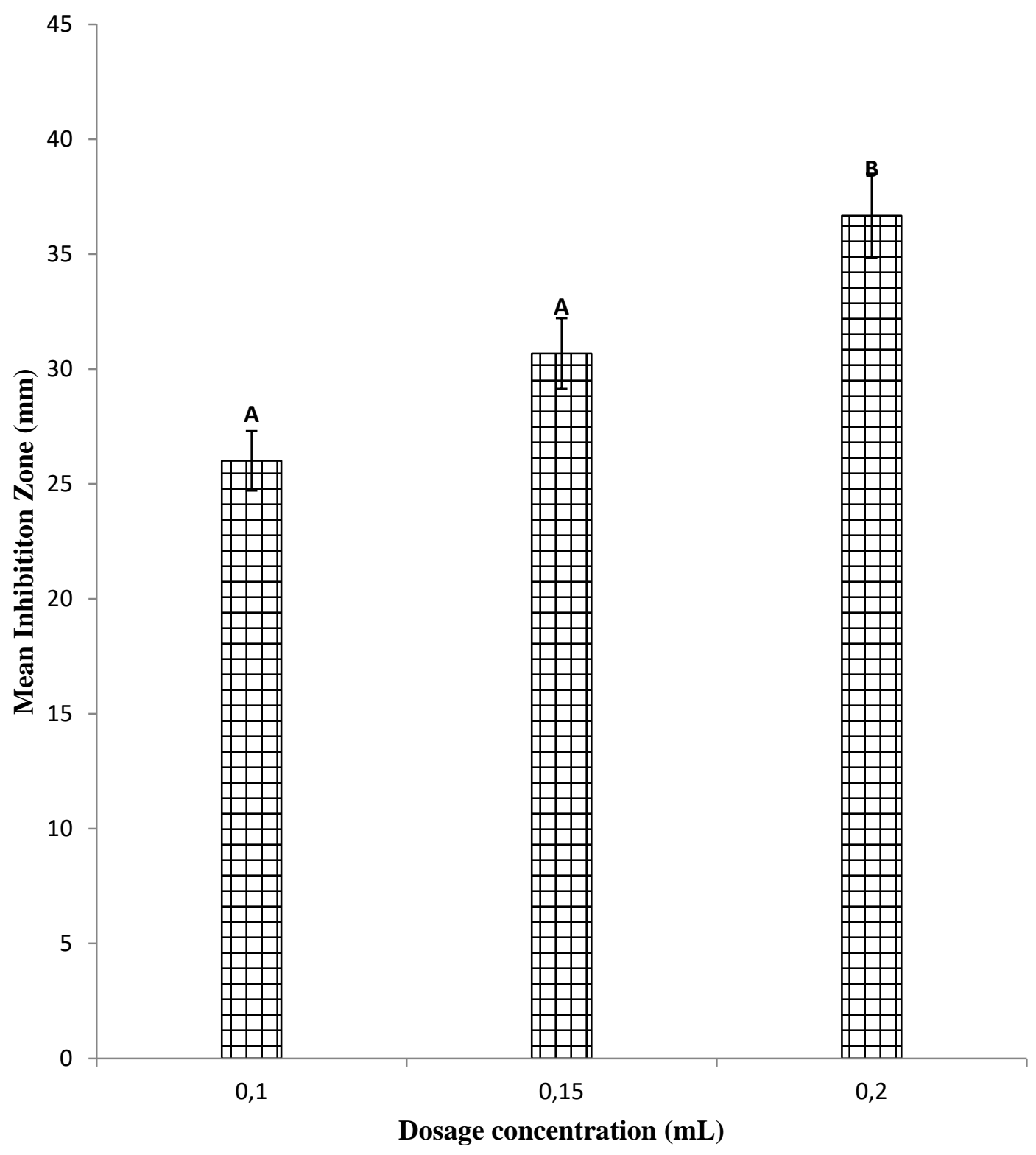

Figure 4. Inhibitory effect of Senna alata on Propionibacterium acnes.

Using the conventional antibacterial drug, highest inhibition was achieved at $0.2 \mathrm{~mL}$ dosage concentration $(31 \mathrm{~mm})$. This was significantly higher than inhibition attained at $0.15 \mathrm{~mL}$
(30 mm) and $0.1 \mathrm{~mL} \quad(26 \mathrm{~mm})$ at $\mathrm{p}<0.05$.

The result of the comparative inhibitory capacity of the four treatments against $P$. acnes is presented in Figure 5. 


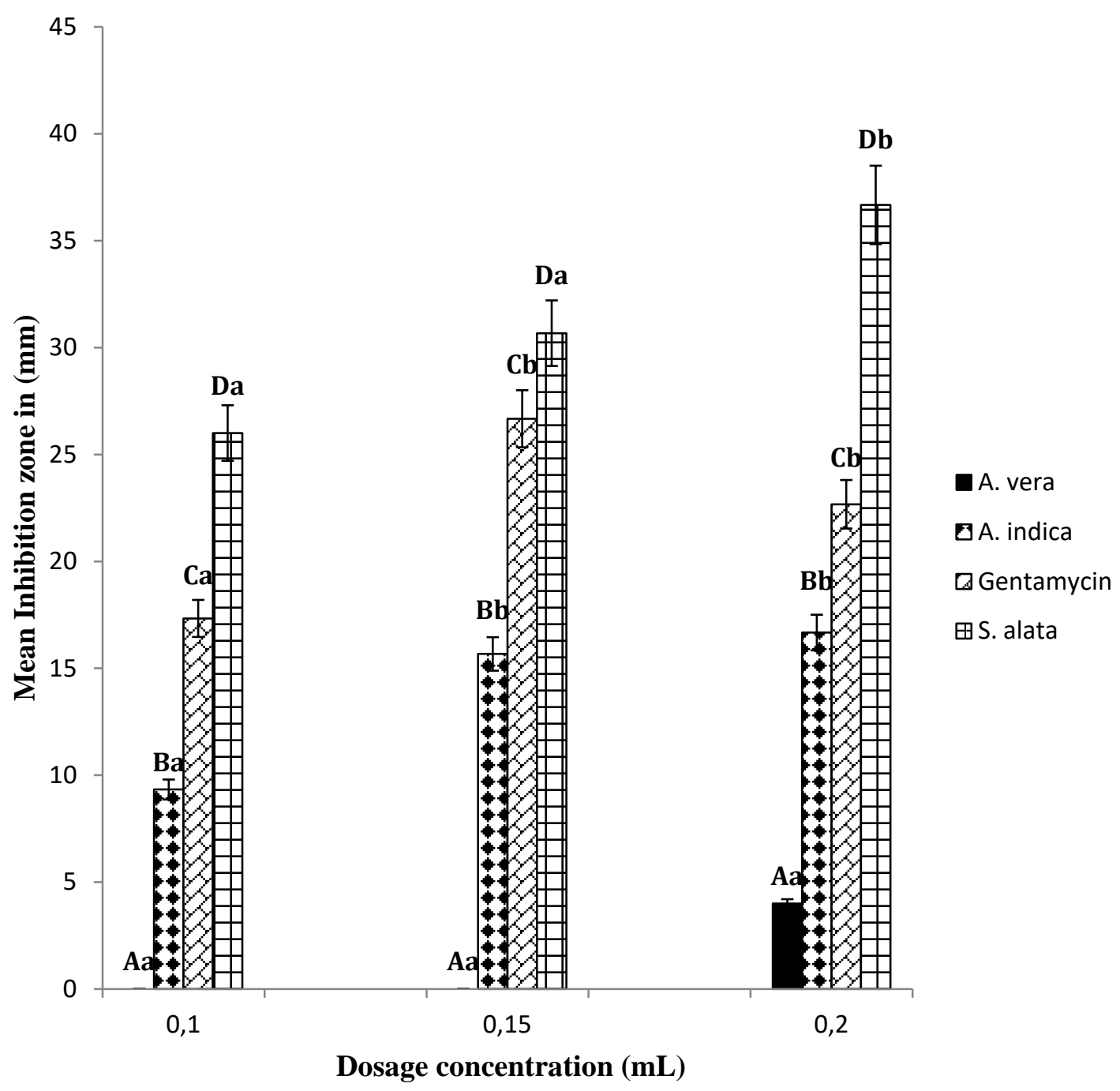

Figure 5. Inhibitory effects of the three plants on Propionibacterium acnes. The capital letter shows the significant difference between the four treatments at the same dosage concentration, while the small letter shows the significant difference between each treatment at different dosage concentration (different letters show significant difference $\mathrm{p}<0.05$ ).

Comparing the four treatments at the three dosage concentration $(0.1 \mathrm{~mL}$, $0.15 \mathrm{~mL}$ an $0.2 \mathrm{~mL}$ ) shows that $S$. alata had a significantly higher inhibitory ability than the other treatments across all levels of dosage concentration at $\mathrm{p}<0.05$. The trend was $S$. alata $>$ Gentamycin $>A$. indica $>A$. vera.

\section{Discussion}

Plants are known to be rich source of antimicrobials. They produce secondary metabolites (phytochemicals), which have demonstrated their potential as antimicrobials when used alone and as synergist or potentiators of other antimicrobial agents (Crozier et al., 2006, Abreu et al., 2012). Phytochemicals like flavonoids, terpenoids and alkaloids have been reported to have antibacterial properties and as such their presence in a plant indicates potential antibacterial capacity of such plant (Cowan, 1999; Herbon, 1999; Pichersky and Gershenzon, 2002). The result of the 
phytochemical analysis of the three plants showed that all of them contain at least one of these phytochemicals which makes them antimicrobial in nature.

Masamichi et al. (1980) stated the characteristics necessary for the positive identification of Propionibacterium acnes is. P. acnes was described as a relatively slow growing bacterium (takes up to 3-4 days before a visible colony can be seen) that is aerotolerant and anaerobic, named after its ability to generate propionic acid. It is a gram positive bacterium characterized by its rod- like shape and always tests positive to the following biochemical tests; catalase, indole, nitrate, gelatin hydrolysis, gram staining and litmus milk. It also forms a glistering milk colour on Chocolate Blood Agar (CBA) and Tryptic Soy Agar (TSA). The result of the biochemical and physical test of the cultured micro-organism satisfies all the stated conditions of Masamichi et al. (1980) needed for the identification of Propionibacterium acnes.

From the result, $A$. vera showed little to no inhibition especially at lower dosage concentrations. This might be due to the low quantity of the antimicrobial compound in its crude gel. At a higher dosage concentration, the plant gel might be effective as seen at $0.2 \mathrm{~mL}$ which produced $4.0 \mathrm{~mm}$ diameter zone of inhibition. Lalla et al. (2001) noted that extracts of $A$. vera have anti-bacterial and anti-inflammatory properties. This has also been confirmed by Sampath et al. (2010) who reported that $A$. vera gel has anti-inflammatory property, good burn and wound healing property. $\mathrm{He}$ also reported that the bark extract have minimal anti-acne effect on $P$. acnes.

Ethanol extract of Azadirachta indica has been reported by Nasri et al. (2015) to have potential for inhibiting acne when used on an anti-acne formulation. Results from this study showed that $A$. indica has anti-acne capability. The inhibitory effect of the plant showed significant increase $(p<0.05)$ with each increase in dosage concentration.

Senna alata is a good source of antimicrobials. It has strong antibacterial properties which may be due to the possession of the three plant chemicals that indicates antimicrobial ability. The anti-microbial ability of this plant had been reported by (Chomnawang et al., 2005; Owoyale et al., 2005; Pukumpuang et al., 2012). There was progressive increase in the amount of inhibition of P. acnes achieved as the dosage concentration increased from $0.1 \mathrm{~mL}$ to $0.2 \mathrm{~mL}$. This increase was statistically significant $(p<0.05)$. The plants showed better anti-acne property than any of the other plants used. It even showed better inhibition than the synthetic antibiotic used (Gentamycin).

Gentamycin is a synthetic antibiotic. It is known to be one of the most popular over the counter (OTC) antibiotics used in the treatment of acne. It is made of synthetic chemical that are antimicrobial. Its anti-acne properties were reported by (Ericsson and Sherris, 1971; Hoeffler et al., 1976). The result of this study revealed that the drug is effective in the inhibition of the growth of $P$. acnes.

A comparison of the three plant extract used shows that $S$. alata, has the highest inhibitory property, followed by $A$. indica. Crude extract of $A$. vera seem to have a negligible to no effect at low dosage concentration $(0.1 \mathrm{~mL}$ and $0.15 \mathrm{~mL}$ ) contrary to the popular opinion in Nigeria that $A$. vera gel can be used in the treatment of acnes. The comparison of the antimicrobial properties of the three plant extracts to a synthetic antibiotics (Gentamycin $10 \mu \mathrm{g}$ ), showed that $S$. alata was significantly more effective than all, even to Gentamycin at all dosage concentrations. A. indica and $A$. vera on the other hand had lesser inhibitory effect on the growth of P. acnes when compared to Gentamycin (Figure 4). S. alata and $A$. indica have been reported to inhibit the growth of $P$. acnes in vitro (Pukumpuang et al., 2012), but 
no literature has been able to show that $S$. alata has a higher inhibitory property than $A$. indica.

\section{Conclusion}

Azadirachta indica and Senna alata are profoundly anti-microbial; capable of inhibiting the growth of Propionibacterium acnes, with both extensive folklore as well as literature supporting their use. This research has been able to confirm the effectiveness of $S$. alata and $A$. indica in inhibiting the growth of $P$. acnes. A. vera has also been shown not to be effective in the inhibition of the growth of $P$. acnes.

\section{Conflict of interest}

The authors declare that they have no conflict of interest in the publication.

\section{References}

Abreu, A. C.; Mcbain, A.J.; Simões, M. Plants as sources of new antimicrobials and resistance-modifying agents. Natural Product Report, v. 29, p. 1007-1021, 2012.

Chomnawang, M. T.; Surassmo, S.; Nukoolkarn, V.S.; Gritsanapan, W. Antimicrobial effects of Thai medicinal plants against acne-inducing bacteria. Journal of Ethnopharmacology, v. 101, no. 1/3, p. 330333, 2005.

Cowan, M. M. Plant products as antimicrobial agents. Clinical Microbiology Reviews, v. 12 , p. $564-582,1999$.

Crozier, A., Clifford, M.N. and Ashihara, H. Plant secondary metabolites occurrence, structure and role in the human diet. Oxford: Blackwell Publishing, p. 475-585, 2006.

Ericsson, H. M.; Sherris, J. C. Antibiotic sensitivity testing. Report of an international collaborative study. Acta Pathol Microbiol Scand B Microbiol Immunol., v. 217, no. 1, p. 27-30, 1971.

Hanna, S.; Sharma, J.; Klotz, J. Acne vulgaris: More than skin deep. Dermatology Online Journal, v. 9, p. 8, 2003.
Harborne, J. B. Classes and functions of secondary products from plants. In: Walton, N. J.; Brown, D. E. (eds.). Chemicals from Plants. London: Imperial College Press, 1999. p. 1-25.

Heinrich, M.; Barnes, J.; Gibbons, S.; Williamson, E. M. Fundamentals of pharmacognosy and phytotherapy, 1. ed. Edinburgh: Churchill Livingstone, 2004, p. 245-252.

Hoeffler, U.; Ko, H. L.; Pulverer, G. Antimicrobial susceptibility of Propionibacterium acnes and related microbial species. Antimicrobial Agents and Chemotherapy, v. 10, no. 3, p. 387-394, 1976.

Pukumpuang, W.; Thongwai, N.; Tragoolpua, Y. Total phenoloic contents, antibacterial and antioxidant activities of some Thai medicinal plant extract. Journal of Medicinal Plants Research, v. 6, no. 35, p. 4953-4960, 2012.

Kim, J.; Ochoa, M. T.; Krutzik, S. R.; Takeuchi, O.; Uematsu, S.; Legaspi, A. J. Activation of toll-like receptor 2 in acne triggers inflammatory cytokine responses. Jounal of Immunology, v. 169, p. 1535-1341, 2002.

Lalla, J. K.; Nandedkar, S. Y.; Paranjape, M. H.; Talreja, N. B. Clinical trials of ayurvedic formulations in the treatment of acne vulgaris. Journal of Ethnopharmacolology, v. 78, no. 1, p. 99-102, 2001.

Nasri, H.; Bahmani, M.; Shahinfard, N.; Nafchi, A. M.; Sabrerianpour, S.; Kopaei, M. R. Medicinal plants for the treatment of acne vulgaris: A review of recent evidences. Jundishapour Journal of Microbiology, v. 8, no. 11, e25580, 2015.

Owoyale, J. A.; Olatunji, G. A.; Oguntoye, S. O. Antifungal and antibacterial activities of an alcoholic extract of Senna alata leaves. Journal of Applied Science and Environmental Management, v. 9, no. 3, p. 105-107, 2005.

Pichersky, E.; Gershenzon, J. The formation and function of plant volatiles: Perfumes for pollinator attraction and defense. Current Opinion in Plant Biology, v. 5, p. 237-243, 2002.

Serrentino, J. How natural remedies work. Point Robert: Harley and Marks Publishers, 1991, p. 20-22.

Swanson, J.K. Antibiotic resistance of Propionibacterium acnes in acne vulgaris. 
Dermatology Nursey, v. 15, no. 4, p. 359-362, 2003.

Siddiqui, A. A.; Ali, M. Practical Pharmaceutical Chemistry. 1. ed. New Delhi: CBS Publishers and Distributors, 1997. p. $126-131$.

Thiboutot, D.; Gollnick, H.; Bettoli, V.; Dréno, B., Kang, S.; Leyden, J. J. New insights into the management of acne: An update from the global alliance to improve outcomes in acne group. Journal of American Academy of Dermatology, v. 60, no. 5, p. 1-50, 2009.

(CC) License information: This is an open-access article distributed under the terms of the Creative Commons original work is properly cited. 